DOI: $10.26677 /$ TR1010.2021.844

Journal Homepage: https://www.journalbusiness.org

\title{
Spotlight on Corporate Social Responsibility Thought in the Field of Non-Profit Public Sector Institutions: An Initiative to Promote CSR Thought in Libya
}

\author{
Younis A. Battal Saleh \\ B.Sc.-M.Sc.-CPA-CEA, Public Accountant , Expert Accountant And Consultant For Court Of \\ Appeal In Benghazi-Libya \& Lecturer And Researcher In Training Department In HRM Of \\ General Electricity Company "GECOL" In Benghazi-Libya .battalsaleh@yahoo.com \\ https://orcid.org/0000-0002-4209-3132
}

\begin{abstract}
The poor performance of the NPPSIs in Libya, which can be described as a catastrophic performance, is the result of the NPPSIs' flagrant failure to adhere to their social responsibilities towards the Libyan community. Problem: In a developing country such as Libya, the culture of CSR is almost completely non-existent, especially in the NPPSIs. The features of this thought are not clear to most NPPSIs until it is adopted. Purpose: To promote the idea of social responsibility in the NPPSIs, the features of this thought must be clearly defined and described in addition to determining how to evaluate the extent of these NPPSIs 'commitment to their responsibility. This is what this study seeks to achieve. Method "an innovative approach to reinforce the theory of CSR": The researcher used the idea of the purpose of establishing the institution in determining the content of economic responsibility, as well as the idea of economic capacity in determining the type of philanthropic responsibility. This study suggested adopting one of the concepts of managerial economics- which is the lost opportunity cost and economic savings, to evaluate the quality of financial decisions, "financial transactions and deals." In order to evaluate the extent of the institution's commitment to its legal and ethical responsibility, the researcher recommends the need to adopt a method of comparison between the content of financial transactions, financial and administrative decisions, behaviors, practices, and requirements and directives contained in local laws, international instruments, noble human values, codes of ethics and professional conduct rules. Result: Theoretically, this study was able to define the features of social responsibility for NPPSIs, along with a description of how to evaluate the social performance of these NPPSIs in a logical manner. Originality/Value: The researcher expects that this study will receive great attention from officials in the Libyan state and leaders of the NPPSIs, as it will serve as a call to promote the idea of social responsibility in all NPPSIs. The researcher also expects the development of methods and procedures that can be used by departments of social performance evaluation in the NPPSIs in Libya to keep pace with the process of promoting social responsibility idea in these NPPSIs.
\end{abstract}

Keywords: Non-Profit Public Sector Institutions. Social Responsibilities. Effectiveness And Efficiency. Managerial Economics. Development. 


\section{INTRODUCTION}

Scholars have increasingly been studying the impact of CSR as a business strategy in for-profit institutions, and results frequently indicate benefits to the organizations such as increased reputation, sales, and reduced reputation damage during crises. Little is known about the impact of CSR on organizations from the nonprofit sector (Waters and Ott, 2014:1). The researcher confirms that the goal of establishing the institution plays a major role in determining the impact of social responsibility on these institutions. The aim of establishing a profit-making institution is to achieve profit (economic gains for owners), and thus the effect of commitment to social responsibility by these institutions lies in enhancing the competitive advantage that contributes to maximizing profit, especially in developed countries where markets are competitive. As for the purpose of establishing a non-profit institution is to provide free or almost free services with high quality to those who deserve it and at the lowest possible cost, taking into account compliance with all local laws and international instruments during the exercise of activities to achieve that goal in addition to commitment to noble human values, codes of ethics and professional conduct rules. The final result of the commitment or lack of commitment of these institutions is reflected in the satisfaction or dissatisfaction of society with the performance of these institutions. Failure to adhere to social responsibility may mean wasting economic resources, "public money and human resources," and the growth of negative phenomena such as corruption within society. Moreover, the lack of commitment to social responsibility also negatively affects the country's economy, and this happens when the services - provided to those who deserve it, are of low quality. The matter that prompts people to buy these services from other countries "as is the case in Libya", and the consequent economic problems represented in the exit of hard currency outside the borders of the state. Based on this analysis, it can be said with almost total certainty that, the impact of the commitment to social responsibility is not on the non-profit institution in the public sector, but on society, as a financier of this institution and not as is the case in the for-profit sector institutions, where the most affected party are the owners or shareholders. Compared with the private sector, the reader will note that there are few scientific writings that have reviewed the issue of the social responsibility for NPPSIs, for the following reasons:1) Many governments resorted to privatization in the 1980s and 1990s to remedy the perceived problems of providing public services;2) Mostly, public sector institutions are directly subject to government oversight and its regulatory agencies;3) Mostly, the activities carried out by these institutions are harmless to the environment;4) There is no material philanthropic responsibility in such institutions;5) The lack of interest of scholars in issuing scientific initiatives to define the content of the economic responsibility of these institutions" lack of clarity of economic responsibility in these institutions." The researcher believes that the reasons that led to scholars' interest in writing on the topic of social responsibility for profitable private sector enterprises are:1) The for-profit private sector institutions are far from the eyes of direct government oversight; 2) Environmental pollution caused by the for-profit private sector institutions is much more than that caused by public sector institutions; 3) Profitable private sector institutions are more problematic in relation to rights and social justice compared to public sector institutions;4) The social responsibilities of the for-profit private sector enterprises are defined and clear, and not as is the case for public sector institutions.

\section{Throwing the Spotlight on the Problem}

In general, the culture of CSR is not prevalent within Libyan society. In a more precise sense, the culture of social responsibility is almost non-existent in profit and non-profit organizations. Wasting public money, corruption, mediation and favoritism are all bad characteristics that characterize the non-profit public sector in Libya. The low level of services provided to the public has created a state of discontent among the general population in Libya. Libyan society's 
dissatisfaction with the poor performance of the NPPSIs especially in recent years is due to the poor services provided by these institutions to the beneficiaries. As well as the resentment and complaint of the employees of the NPPSIs resulting from their failure to obtain their material and moral rights and their harsh criticism that never ceases in all social media, which often amount to the point of describing the NPPSIs' leaders as the corrupt elite, which puts more than one question mark about all the leading personalities in these institutions. The frequent dismissals and appointments- replacement of leaders, to leadership positions, that take place at the level of senior management and executive management in these institutions. All of the above indicates that the NPPSIs are not committed to their social responsibility towards the Libyan society. To promote and entrench the idea of social responsibility in the NPPSIs in Libya, the features of that thought must be defined for these institutions. The main features of this thought are unclear to NPPSIs, especially since the thought of social responsibility was mainly associated with the institutions of the private sector (the for-profit sector) and developed through them. The culture of social responsibility of profit and non-profit organizations has not yet been entrenched within Libyan society. The adoption of the idea of social responsibility by the NPPSIs in Libya is still like a cake in the sky. This thought did not have a good chance to be a scientific subject taught in universities and higher institutes during the eighties and nineties of the last century and up to the present time. This deficiency contributed to the low level of knowledge about this thought among most of those working in the NPPSIs. The general idea or public perception in the minds of most people about the concept of social responsibility is limited to charitable donations made by private sector institutions to the communities in which they operate, while the thought of social responsibility goes further than that. This misconception may be responsible for the lack of a clear vision of social responsibility in NPPSIs. The absence of a culture of social responsibility with clear features in the Libyan society" in general" and in the NPPSIs "in particular" contributed to the lack of interest of these institutions in instilling the idea of social responsibility within their walls and buildings. That is why the NPPSIs do not disclose their social performance and social responsibility policies in their financial reports and statements. In the future, if that culture and idea of social responsibility are allowed to become entrenched in the NPPSIs, another problem will arise, which is how to evaluate the social performance of these institutions to determine the extent of their commitment to their social responsibilities.

\section{The Purpose of the Study}

This theoretical study aims to define the features of CSR thought in the NPPSIs. To achieve this goal, an accurate definition of social responsibility must be found, which is in harmony with the nature of the role of these institutions in contemporary societies. As well as defining the dimensions of that responsibility, its types and the contents of these types, with an explanation of how to evaluate social performance in these non-profit institutions. Therefore, this study will be concerned with determining the following:

1) An accurate definition of the social responsibility of the NPPSIs and its dimensions.

2) The types of social responsibilities of the NPPSIs and their contents.

3) How to evaluate the social performance of the NPPSIs.

\section{The Importance of Studying}

Defining the features of the idea of the social responsibility of the NPPSIs by describing its theoretical construction and intellectual content will contribute to the understanding and the adoption of this thought by the Libyan authorities, leaders and workers in NPPSIs with ease and without any difficulties. The adoption of this idea by the NPPSIs in Libya will contribute to improving the performance of these institutions and pushing forward the wheel of the 
development and growth in Libya. Also, strengthening the presence of this thought in the NPPSIs will contribute to developing social responsibility policies and improving internal control systems to include how to evaluate the social performance of these institutions through a specific package of procedures and methods necessary for that.

\section{The Study Methodology}

The literature review will include a statement of the content of the social responsibilities of the forprofit sector institutions. In addition to the role of internal audit departments in evaluating the level of commitment of NPPSIs to their social responsibility, With reference to the five deviations that affect the quality of these institutions 'commitment to their social responsibilities, namely: 1) The deviation from planned economic performance;2) The deviation from the economic rationality;3) The deviation from the financial and administrative policies;4) The deviation from the codes of ethics and professional conduct rules;5) The deviation from the local laws and International instruments.

\section{Method "An Innovative Approach to Reinforce the Theory of CSR"}

To determine the differences between the features of the CSR in the for-profit sector and the nonprofit sector, the researcher used the idea of the goal of establishing the institution for the purpose of determining the content of the institution's economic responsibility, as well as adopting the idea of financial capacity "economic capacity " and the idea of the goal of establishing the institution for the purpose of determining the type of philanthropic responsibility of the institution. To evaluate the commitment of the NPPSIs to their economic responsibility, the quality of financial decisions must be evaluated to judge the efficiency of the administration in using the available economic resources "good use of public money and human resources." This study indicated the importance of adopting the concept of lost opportunity cost " the concept of economic savings" by internal audit departments to evaluate financial transactions to judge the extent of commitment to economic responsibility. To achieve this, the researcher developed a method that simulates decision-making steps as follows: 1) Determining the desired benefit of the financial transaction "financial decision";2) Determining the available alternatives to achieve that desired benefit;3) Choosing the best alternative that achieves that desired benefit with the highest degree of efficiency "at the lowest cost". For example, to evaluate financial transactions related to the purchase of hotel services "providing accommodation for delegations from outside the city of Benghazi." The desired benefit from this transaction must be precisely defined, which is the provision of housing and accommodation for the delegation. The alternatives available to achieve this desired benefit are "hotel accommodation - staying in the NPPSI's houses - renting a house for delegations. All of these alternatives achieve the same quality of service. " The ideal choice will depend on the cost factor and the quality of service. The best alternative is the one that achieves the same quality of service at the lowest cost. The researcher also used the necessity criterion in evaluating financial deals. More precisely, was there a need to conclude a financial deal? The researcher relied on some managerial economics concepts to evaluate the quality of financial decisions and to judge the efficiency of the administration in the use of public money, such as the concepts of effectiveness and efficiency, lost opportunity cost, and economic savings. As well as evaluating the quality of financial and administrative policies by studying the extent of their consistency with prevailing conditions, local laws and international instruments. As for the evaluation of legal and ethical responsibilities, the matter will depend on the extent to which the content of decisions, policies, deals, practices and behaviors is consistent with local laws, international instruments, codes of ethics and professional conduct rules.

\section{LITERATURE REVIEW}


"Corporate social responsibility (CSR) indicates to strategies and polices that corporations put into action as portion of corporate governance that are designed to ensure the corporation's operations are legal and ethical and beneficial for community " (CFI, n.d. ). For several decades now, the CSR is in the spotlight. Where CSR is not a new notion, only it was under the lack of awareness and appropriate regulatory authorities to monitor. This is the reason still CSR is not having a universally defined definition and clear features. So CSR is under discussion and controversy ( Deore, et al.2016:96 ). The researcher describes the theory of CSR as a plane that took off from the airport runway and did not settle in the air yet. CSR has taken on an increasingly distinguished role in the business world in recent decades, especially after realizing that it is an important tool for creating the development within contemporary societies. CSR has grown so popular that nearly every major company in the U.S. now integrates a significant commitment to social and/or environmental programs into its business model. CSR can be loosely defined as the adoption of socially beneficial and environmentally sustainable practices by corporate actors. The rise of CSR can be attributed to growing public disenchantment with traditional business practices that degrade the environment and compromise worker wellbeing, and resulting pressure from consumers and nonprofits on the private sector to reform itself. Instead of simply complying with government regulation, a company that is "socially responsible" adopts more stringent selfregulation ensuring that it is acting to minimize negative impact on the environment, its employees, its customers, and the community (Leedy, 2009:2).

Social Responsibilities of Private Sector Institutions " Corporate Social Responsibilities"

CSR have been categorized by scholars into four main types as follows: economic responsibility; legal responsibility; ethical responsibility; philanthropic responsibility. There is no controversy about this classification. This classification is considered reasonable and accepted in the scientific community.

\section{Economic Responsibility}

The researcher divides the corporate economic responsibility according to their impact into:

1) Corporate Economic Responsibility at the Level of the Corporation's Economy: Economic Responsibilities: "Be profitable, maximize revenues and minimize expenses." Economic responsibilities relate to business's provision of merchandise and services in community. Earnings result from this activity and are necessary for any other responsibilities to be carried out. It is assumed that corporations will be as profitable as possible, maintain a powerful competitive position and maintain a high level of operating efficiency. It is well known that many developing countries suffer from a shortage of foreign direct investment, as well as from high unemployment level and widespread poverty. It is no surprise, therefore, that the economic contribution of companies in developing countries is highly prized, by governments and communities, alike (Carroll, 1991: 40; Al Am, 2020:334).

\section{2) Corporate Economic Responsibility at the Level of the Country's Economy as a Whole}

This concept should be strengthened and adopted in developing and poor countries, which particularly states the following: " when seeking to maximize profits, corporations must not harm the national economy of the state, even if the laws do not criminalize this. " Corporations should contribute to strengthening the national economy of the state, "strengthening the state's national wealth." Corporations are one of the main components of any country's economy, and they can influence it, either positively or negatively. We may applaud the profitable corporation" the company that made the highest profit, " and at the same time we may regret the negative effects that this corporation has left at the level of the country's economy as a whole. For example, hiring foreign workers and ignoring national workers. This behavior " action" contributes to increasing unemployment rates in society and also contributes to the exit of hard currency outside the borders 
of the state. Another example, reducing sales prices in order to sell a larger quantity of products may contribute to pushing another competitor out of the market. Corporate economic responsibility can be viewed from two angles: maximizing the company's profit and strengthening the national economy of the state ( Saleh,2021:50).

Legal Responsibility: "Obey the laws and Regulations"

Corporate legal responsibility is the corporation's compliance with local laws and international instruments while practicing its activities to achieve its goals. The activities carried out by Institutions in various sectors "for profit and non-profit" in order to achieve their goals must be consistent with the financial and administrative policies and regulatory controls and procedures "the financial and administrative regulations of the institution." Violating these policies creates chaos within these institutions. These institutions must comply with local laws, such as tax laws, customs laws, social security laws, labor laws, working women's rights laws, workers' rights laws, environmental protection laws, consumer protection laws and service recipients, etc. These institutions must comply with international instruments issued by global or international organizations, such as those issued by the United Nations, the World Health Organization, the International Labor Organization, the International Standardization Organization, etc. The state and its institutions are part of the global system. Compliance with these charters means not violating the international legal order and desire specified in those conventions.

1) Legal Laws:

The Institutions in various sectors "for profit and non-profit" are free to do business " to achieve their goals" however they want but only within the limits of regulations and national laws such as labor law, environmental law, etc. Failure to respect laws by an institution leads to chaos and loss of rights within the community in which the organization operates. All organizations must work within the framework of laws and regulatory legislation and not to deviate from that framework in order to preserve private and public interests.

\section{2) International Instruments}

Respect for laws and regulations is not limited to local laws" national legislation," but includes laws and international instruments issued by international organizations such as the United Nations, International Labor Organization, etc. The country in which the business organization operates is part of the international system, and in order not to have any problems with the international community, all laws and international instruments must be respected. These charters contain general directives and instructions on specific topics that must be followed and not violated. Also, the local laws must be in conformity with all the directives and instructions contained in those international instruments. The aim of adhering to these instruments is to promote the concepts of justice, peace, freedom, safety and well-being for all peoples of the world, wherever they are, as they are an integral part of the international community.

\section{Ethical Responsibility: "Be ethical "}

The normative expectations of most societies hold that laws are essential but not sufficient. In addition to what is required by laws and regulations, society expects businesses to operate and conduct their affairs in an ethical fashion. Taking on ethical responsibilities implies that organizations will embrace those activities, norms, standards and practices that even though they are not codified into law, are expected nonetheless. Part of the ethical expectation is that businesses will be responsive to the "spirit" of the law, not just the letter of the law. Another aspect of the ethical expectation is that businesses will conduct their affairs in a fair and objective fashion even in those cases when laws do not provide guidance or dictate courses of action. Thus, ethical responsibilities embrace those activities, standards, policies, and practices that are expected or 
prohibited by society even though they are not codified into law. The goal of these expectations is that businesses will be responsible for and responsive to the full range of norms, standards, values, principles, and expectations that reflect and honor what consumers, employees, owners and the community regard as consistent with respect to the protection of stakeholders' moral rights. The distinction between legal and ethical expectations can often be tricky. Legal expectations certainly are based on ethical premises. But, ethical expectations carry these further. In essence, then, both contain a strong ethical dimension or character and the difference hinges upon the mandate society has given business through legal codification (Carrol,2016:3). The activities carried out by the Institutions in various sectors "for profit and non-profit" - in order to achieve their goals, must be consistent with the noble human values and the code of ethics and the rules of professional conduct. These institutions must combat administrative and financial corruption. These institutions should contribute to promoting social justice among employees "equal opportunities for all". These institutions must prevent all forms of racial discrimination within their walls, etc.

\section{Philanthropic Responsibility: " Be a good corporate citizen"}

"Philanthropic responsibility can include things such as funding educational and cultural programs, supporting health and social welfare initiatives, donating for humanitarian or development reasons, and supporting community beautification projects" (CFI,n.d.). It is the moral and material support that companies provide to the society in which they operate. It involves being a good corporate citizen and including active participation in acts or programs to promote human welfare or goodwill (AlAm, 2020:335). Corporate philanthropy is the material and immaterial sacrifices that corporations make for the benefit of other entities outside the walls and buildings of those corporations, without waiting for any economic benefits other than enhancing the competitive advantage. Corporate philanthropy in its broadest sense means improving the quality of life for the community or one of its sects by providing a helping hand and material and nonmaterial assistance to all parties outside the corporation's walls and buildings( Saleh,2021:48).

\section{Features of the Thought of Social Responsibility for NPPSIs}

The nature of the activity of NPPSIs and their objectives differ from the for-profit institutions. Therefore, the features of social responsibility will differ in the two sectors, "profit and nonprofit." The difference will lie in the content of economic responsibility and the type of philanthropic responsibility.

\section{Non-Profit Public Sector Institutions" NPPSIs"}

After the emergence of the Marxist Socialist Ideology - which calls for a welfare state, which permits the state authorities to administer all economic activities, with its commitment to provide all goods and services to citizens to achieve justice and equality and redistribute income among the classes of society in the interest of the destitute class (Aljamal,2016:1688). At the present time, many countries of the world - including Libya, are adopting the idea of the partnership between the public and private sectors in managing their economic systems due to the inability of the governments of those countries to manage the affairs of all economic activities on their own without involving the private sector.

The NPPSIs are the part of the country's economy and one of its main pillars, that is controlled and financially supported by the government, and which aims to provide free or almost free services to the general population or certain groups in the society in order to improve the quality of life and achieve prosperity for them.

\section{Definition of Social Responsibility for NPPSIs}


The researcher defines the social responsibility of the NPPSIs as follows: The social responsibility of the NPPSIs means achieving the institution's goals effectively and efficiently in accordance with local laws, international instruments, noble human values and the code of ethics and the rules of professional conduct.

\section{Interpretation of the Definition}

In socialist societies " in which the state's economy depends on public sector institutions" or societies that adopt the socialist and capitalist system together "in which the state's economy depends on public and private sector institutions", people benefit from the free or almost free benefits and services provided by NPPSIs for them. In most cases, these institutions are fully funded by the state treasury to provide certain benefits and services to the citizens of the state. Citizens can judge the performance of these institutions by the quality of those services and the benefits provided to them. Societies provide their economic resources to these institutions to manage them in a rational manner or with economic rationality that meet the citizens' needs for services and benefits, which are supposed to be of a high degree of quality. On that, it can be said that NPPSIs are established by societies with the aim of providing free or almost free services to those who deserve them with high quality (effectiveness, which means providing services with high quality, which is the goal that these institutions strive to achieve) and at the lowest possible cost (efficiency, which means economic rationality or good use of economic resources). The activities carried out by these institutions - to achieve their desired goals, must be compatible with all local laws, such as labor laws, tax law, social security law, etc., as well as international instruments, such as instruments issued by the United Nations, International Labor Organization, World Health Organization, International Standardization Organization, etc. Also, the activities carried out by these institutions - to achieve their desired goals, must be compatible with all the noble human values, and code of ethics and the rules of professional conduct.

\section{Social Responsibilities of NPPSIs}

NPPSIs must adhere to four types of social responsibilities, are: economic, legal, ethical, and nonmaterial philanthropic. With regard to NPPSIs, there is a difference in the meaning of economic responsibility, as it does not mean profit maximization as it is the case for private sector institutions" for profit-oriented institutions". There is no material philanthropic responsibility in the list of social responsibilities of the NPPSIs because these institutions are non-profit organizations, they do not seek to achieve profit, and therefore they have no obligation to this responsibility, which requires economic resources to finance it, but they can engage in non-material charitable activities "such as consultations, trainings and workshops, etc. " In a more specific sense, the social responsibilities that must be adhered to in the private sector (the for-profit sector) are the same responsibilities that must be adhered to in NPPSIs with a difference in the meaning and manner of commitment in relation to economic responsibility and philanthropic responsibility between the for-profit and non-profit sectors.

Economic Responsibility: It means the proper use of the available economic resources - efficiently achieving the goals of the institution, or the optimum utilization of the available economic resources (the economic rationality), and the provision of high-quality services to those who deserve them. In the event that citizens do not obtain high-quality services, it may contribute to those citizens resorting to request those services from other countries. For example, the low quality of health services provided by Libyan public hospitals has contributed to hundreds of thousands of citizens leaving the Libyan borders to seek health care in neighboring countries such as Tunisia and Egypt. This failure led to the transfer of millions of dollars in favor of hospitals in those 
countries, which resulted in a decrease in the amount of the foreign exchange within the Libyan state and the emergence of many economic problems associated with that decrease.

Non-Material Philanthropic Responsibility: It is the moral "non-material" charitable activities that are provided by the NPPSIs to the communities in which they operate and which do not require the payment of funds or assets in order to achieve them, such as students' training, providing advice to other governmental and non-governmental bodies and organizations, educating the community about some issues, etc.

\section{Dimensions of the Social Responsibility for NPPSIs}

There are five dimensions of the social responsibility for NPPSIs are:

\section{The Economic Dimension}

The institution must fulfill its economic responsibility towards the community that funds it, by committing to the following: 1) The proper use of the available economic resources - efficiently achieving the goals of the institution, or the optimum utilization of the available economic resources (the economic rationality); 2) The provision of high-quality services to those who deserve them.

\section{The Legal Dimension}

As a regulated and compliant entity, the institution has to meet its legal responsibility towards the local and international community, through commitment to the following: 1) Compliance with administrative and financial policies of the institution "internal administrative and financial regulations "; 2) Compliance with local laws; 3) Compliance with international instruments. The institution must comply with the contents of the international conventions issued by international organizations, especially if the country to which the institution belongs is a member of those organizations- those contents that are supposed to be included in the local laws of the member state.

\section{The Ethical Dimension}

Ethical dimension refers to behaviors and activities that are permitted or prohibited by organization members, community, society, even if they are not codified by law ( Nicolae and Sabina,2010:238). The ethical dimension means the exercise of activities by organizations to achieve their desired goals in accordance with codes of ethics and professional conduct rules. When it comes to pursuing stated goals, fulfilling local commitments, organizations should consider the following ethical requirements: 1) Keeping away from all practices that may distort social justice in the society and that may cause moral harm to others; 2 ) Keeping away from all immoral practices and behaviors that offend the moral system of a society; 3) Respecting the customs, traditions, cultures and religions of the society. In short, staying away from everything that is not accepted by a society and that may provoke its dissatisfaction, even if it is not indicated in the laws.

\section{The Philanthropic Dimension}

NPPSIs are institutions financed by the state treasury to cover their own expenses in order to provide free services to the beneficiaries. These institutions do not achieve profits through which they can make in kind donations to the community in which they work, but they can participate in the development of that community through volunteer activities that do not require the payment of money or the provision of assets such as training students, conducting public awareness and education campaigns to raise awareness about some issues, providing free consultations, etc.

\section{The Environmental Dimension}


All institutions are subject to environmental laws and regulations regarding pollution emissions, the handling of hazardous materials, and the protection of natural resources. Public sector institutions contribute to creating the traffic congestion within cities due to the influx of large numbers of service seekers "entry and exit to and from these institutions," in addition to the large number of workers in these institutions. In view of the health problems caused by crowding for people, these institutions must contribute to addressing the problem of the traffic congestion in a civilized manner. Any government in any country can redistribute the administrative headquarters of these institutions over the entire geographical area of the state in order to revive remote areas and reduce the overcrowding in large cities.

\section{The Desired Goals of Commitment to Social Responsibility by NPPSIs}

NPPSIs' commitment to their social responsibility contributes to achieving the following gains:1) Preserving public funds "optimum utilization of available economic resources"; 2) Providing services to those who deserve it with high quality;3) Promoting the principles of social justice" principles of justice and equality" and basic human rights within and outside these institutions" Promoting the principles of justice and equality and instilling them deeply in all social groups";4) Strengthening the national economy of the state.

\section{Evaluating the Social Performance of NPPSIs}

Internal control departments in the NPPSIs can evaluate the social performance of these institutions by studying the extent of their commitment to their four responsibilities, "economic, legal, ethical, and philanthropic." Economic responsibility can be evaluated by: 1) Study the quality of services provided to those who deserve them, which reflects the extent of the beneficiaries' satisfaction with those services; 2) Study the quality of financial transactions and decisions "or what is known as the good use of available economic resources" to determine whether those transactions resulted in a waste of public money or contributed to achieving economic savings. As well, legal responsibility can be evaluated by: 1) Study the extent to which the institution's executive management follows the established administrative and financial policies to implement the plans necessary to achieve the desired goals; 2) Study the extent to which the institution follows local laws and international instruments while achieving its objectives. As for the ethical responsibility, it can be assessed by studying the decisions issued by the management as well as the behaviors monitored within that institution and the extent of their consistency with the codes of ethics and the rules of professional conduct. Finally, philanthropic responsibility can be evaluated by studying the extent of the institution's interaction with the issues and aspirations of the society in which it operates.

\section{The Role of Internal Control in NPPSIs}

The internal control system is the safety valve for any organization or business - whether in the public or private sector. The internal control system is the first and last responsible for ringing early alarm bells to draw the attention of officials about potential financial risks "financial bottlenecks and low level of economic performance" to discuss the best ways to address them. Given the importance of this system in enhancing the survival and continuation of any business organization in performing its economic activity in the environment in which it operates, especially in the competitive environments, the traditional role of protecting movable and immovable funds from embezzlement" unethical and irresponsible practices" is no longer sufficient to ensure the survival of these organizations. The examination of financial transactions and verification of the approved financial and administrative procedures and policies is only part of the role of internal control in the modern era. The role of the internal control system goes further. It goes beyond the 
documentary examination of financial transactions. In the modern era, with the adoption of the idea of social responsibility by business organizations, the role of the internal control system has evolved to include the evaluation of the organization's social performance in addition to its economic performance. The role of internal audit in the NPPSIs goes beyond documentary examination - as is common practice for the internal audit profession in Libya. Mostly, internal auditing in the NPPSIs in Libya focuses its attention on documentary examination of financial transactions as a failed attempt to preserve public money from theft and embezzlement without evaluating those transactions from an economic perspective. The focus is on embezzlement and not on waste " uneconomical use of available resources."

\section{Financial and Administrative Deviations}

The relationship between the internal control system and the CSR can be explained as follows: The existence of an internal control system in any institution is to ensure that the desired goals are effectively and efficiently achieved. Effectiveness means the percentage of achieving the desired and planned goals by the institution's higher management. As for efficiency, it reflects the extent of the executive management's commitment to the requirements of social responsibility that are considered necessary to achieve these goals. In fact, the evaluation of social responsibilities "economic, legal, ethical, and philanthropic" by the internal control systems is an evaluation of the extent of compliance with the requirements of those responsibilities by the executive management that is concerned with the implementation of the desired goals.

Financial and administrative deviations in the NPPSIs mean that there is a state of total or partial non-commitment to social responsibility. Those deviations that can be detected by the internal control systems are: 1) Positive and negative deviations resulting from comparing actual performance with planned performance; 2 ) Deviation from codes of ethics and professional conduct rules "the practice of unethical behaviors such as theft, embezzlement, etc."; 3 ) Deviation from economic rationality "misuse of available economic resources."; 4 ) Deviation from the approach set for achieving the goals, "violation of administrative and financial policies and organizational procedures."; 5 ) Deviation from local laws and international instruments issued by global organizations.

\section{The Independence of the Internal Audit in the NPPSIs}

Among the common mistakes that undermine the role of internal audit departments in the NPPSIs and that contributed to the exacerbation of the phenomenon of corruption is the lack of independence of these departments and their subordination to the higher managements in those institutions. The higher and executive departments in public institutions are often appointed by the general assemblies of these institutions, as is the case in Libya. Chairman and members of the general assembly of any institution - they are from outside that institution, are chosen by the government to oversee and monitor that institution on behalf of the government and society. The general assembly is responsible for choosing the board of directors of the institution "the senior management" and the general manager of that institution "executive management", who are mainly employees working in that institution. Except when absolutely necessary, the general assembly does not intervene in selecting the leaders of the regulatory systems within the institution. The subordination of the internal audit department is to the higher management "the board of directors of the institution, and the general manager - the executive management," and not to the general assembly. This subordination makes the internal audit department not independent in performing its tasks to the fullest. It will get worse in the absence of direct communication between the internal audit department and the general assembly. Reports with negative implications (the 
bad performance) issued by the internal audit department and which are often not in the interest of the higher management and the executive management of the institution will be obscured and disappeared into the offices of these departments and may result in a change of leaders in the departments and sections of the internal audit of the institution. In order to activate the role of internal audit in public sector institutions, the internal audit departments must be subordinate to the general assemblies, the "as a neutral party", and not the institutions' higher managements.

\section{The Importance of Using Managerial Economics Concepts in the Internal Auditing}

The quality of the financial transactions executed by the executive management cannot be judged unless those financial transactions are subject to study and evaluation from an economic perspective. To evaluate the efficiency of the executive management to judge its performance through executed financial transactions- by the internal audit department in the institution, there are two questions that must be answered for each financial transaction: 1) Was there a need to conclude that financial deal? 2) Did the executive management take into account the concept of the economic rationality when concluding that deal?. The answer to the first question depends on the personal assessment and realistic evaluation of the situation. As for the answer to the second question, it depends on the concept of lost opportunity cost and the concept of economic savings in accordance with the method suggested by the researcher, which simulates the method of decision-making steps as follows: 1) Determining the desired benefit of the financial transaction "financial decision";2) Determining the available alternatives to achieve that desired benefit;3) Choosing the best alternative that achieves that desired benefit- with high quality, with the highest degree of efficiency "at the lowest cost".

\section{RESULTS}

\section{Theoretical Construction" Conceptual Framework" of the Thought of Social Responsibility for} NPPSIs:

1) According to the researcher's perception, any definition of social responsibility for NPPSIs must include the meanings of the following two concepts: effectiveness and efficiency. Effectiveness is the percentage of goal achievement, which means providing services to those who deserve it with high quality. Efficiency is the material and moral" non-material" costs incurred in achieving the goal. Material costs are related to the concept of economic rationality" the efficient and optimal use of the available economic resources ". As for the intangible costs, they are related to the amount of compliance with policies, plans, regulatory procedures, local laws, international instruments, codes of ethics and professional conduct rules.

2) Mostly, the NPPSIs are monopolistic. These institutions operate in a non-competitive environment, so adopting the idea of the social responsibility in these institutions is for the purpose of preserving public economic resources "public money and human resources"; improving the quality of services provided to those who deserve it; promoting social justice; enhancing compliance with the local laws and international instruments; adhering to codes of ethics and rules of professional conduct.

3) After the emergence of the idea of CSR and its adoption in the private and public sectors- as a tool for development, the role of the internal control system in the NPPSIs must evolve from the stage of documentary examination of financial transactions and administrative decisions to the stage of evaluating the extent of commitment to social responsibilities, as follows: evaluation of the economic rationality" economic responsibility "; the evaluation of the compliance with 
administrative and financial policies and regulatory procedures, local laws and international instruments" legal responsibility"; Evaluating the extent of adherence to noble human values, codes of ethics and rules of professional conduct" ethical responsibility."

4) The social responsibility of the NPPSIs (such as hospitals, schools, institutes, universities, electricity companies, government services agencies, cleaning companies, authorities of gardens, parks and recreation areas and museums, water and sanitation authority, security agencies, etc.) differs from the social responsibility of private sector enterprises in terms of the goal of commitment, the first is to gain community satisfaction and the second is to obtain a competitive advantage. Also, the economic responsibility of the NPPSIs differs from that of the private sector, the first is to make good use of available economic resources "public money and human resources" and provide services to those who deserve it with high quality, while the second is to maximize profit. As well as, the number of types of responsibilities in the two sectors is not different" with some modification in the philanthropic responsibility." The social responsibilities of NPPSIs are "economic, legal, ethical, and non-material philanthropic ", while the social responsibilities of private sector institutions are "economic, legal, ethical, and non-material and material philanthropic." the NPPSIs are not for the purpose of maximizing profits, as they receive financial support from the state's public treasury. They specialize in providing free services to people. There are no profits through which to engage in charitable activity that requires payment of funds or assets. Therefore, there is no material philanthropic responsibility in these institutions.

\section{CONCLUSION}

This study contributed to enriching the thought of CSR and removing ambiguities about its features in the NPPSIs. This study identified the different aspects of this thought and its features in the non-profit sector - which differ from its features in the for-profit sector, as follows: 1) The economic responsibility of the NPPSIs has a special meaning and nature that differs from the economic responsibility of for-profit institutions. It means good use of public money, "optimum use."; 2) The philanthropic responsibility of the NPPSIs is nonmaterial, it is moral or intangible" non-monetary philanthropic responsibility." NPPSIs can have a great role in interacting with the issues and aspirations of the societies in which they operate through their involvement in programs and activities of intangible charitable work such as free training for students, providing free consultations, educating the local community, moral support to solve social issues and problems, etc.

To evaluate whether the NPPSIs are committed to their social responsibility towards the communities in which they operate or not, and to issue reports on the social performance of these institutions, specific focus must be placed on studying and evaluating the following five axes by the internal control systems, "internal audit departments" in these institutions, according to concepts of effectiveness and efficiency. Those axes are: 1) Evaluating the quality of financial decisions and deals, "evaluating the level of economic rationality in those decisions and deals."; 2) Evaluating the quality of the actual spending by comparing it with the planned spending; 3 ) Evaluating the quality of administrative and financial policies and their consistency with the goals, plans, and local laws and international instruments; 4) Evaluating the extent to which the specified approach is followed to achieve the goals, " policies and organizational procedures."; 5) Evaluating the extent of compliance with the codes of ethics, and professional conduct rules.

\section{REFERENCES}


Al Am, AlAline (2020). The Lebanese Students' Awareness on the Concept of Corporate Social Responsibility. Athens Journal of Business \& Economics. 6(4), 331-348.

Aljamal, Hashem Mustafa Muhammad Salem (2016). Partnerships between the public and private sectors as a tool to achieve sustainable development. Journal of the College of Sharia and Law in Tanta.31(4), 1686-1749.

Carroll, Archie B. (1991). The pyramid of corporate social responsibility: Toward the moral management of organizational stakeholders. Business Horizons, 34(4), 39-48.

Carroll, Archie B. (2016). Carroll's pyramid of CSR: taking another look. International Journal of Corporate Social Responsibility.1(3),1-8.

Corporate Finance Institute (CFI) (n.d.). What is Corporate Social Responsibility (CSR)? .Retrieved from: https://corporatefinanceinstitute. Com/resources/ knowledge/other/ corporate - socialresponsibility-csr/.

Deore,Sarla Pundlik,Khandare,D.M.,Jadhav,N B (2016).CSR: The Role of Non Profit Organization and voluntary groups for Creation of Better Environment in developing countries.IOSR Journal of Business and Management (IOSR-JBM).18(2),96-99.

Leedy, Darin (2009). Corporate Social Responsibility and Nonprofit Organizations. Economics Theses. University of Puget Sound. Retrieved from: https://soundideas .pugetsound .edu / economics_theses/59

Nicolae,Jucan Cornel and Sabina,Jucan Mihaela (2010).DIMENSIONS AND CHALLENGES OF SOCIAL RESPONSIBILITY.Annales Universitatis Apulensis Series Oeconomica, 12(1),238247. Retrieved from: http://www.oeconomica .uab.ro / upload /lucrari/1220101/23.pdf

Saleh, Younis A. Battal (2021). Corporate Donations as a Source of Financing an Innovative Strategic Economic Plan to Strengthen the National Economy in More Than One Axis in Developing and Poor Countries: A Justified View. Business Innovation \& Entrepreneurship Journal.3(1),45-60.

Waters, R.D. and Ott, H.K. (2014). Corporate Social Responsibility and the Nonprofit Sector: Assessing the Thoughts and Practices Across Three Nonprofit Subsectors. Public Relations Journal, 8(3),1-18. https://repository.usfca. edu/cgi/viewcontent. cgi?article= $1024 \&$ context=pna 